\title{
Taking the Demand of Talent Cultivation as the Traction for Overall Construction of Specialized Courses
}

\author{
Shouhua Chen ${ }^{\mathrm{a}}$, Bo Zhang ${ }^{\mathrm{b}}$, Fusheng Liu \\ Department Acadmy of Armored ForcesEngineering, Beijing 100072, China. \\ abeijingcsh@tom.com, bzb5616@163.com, czb5616@sohu.com
}

Key words: Specialized courses; Courses construction; Demand traction.

\begin{abstract}
Focused on the planning of teaching content system, the innovation of teaching modes, the construction of teaching resources and the building of talent team, how to build a high quality course is explored, which combines the unit of typical construction of specialized courses and highlights how to take the demand of talent cultivation as the traction for overall construction planning of specialized courses, in order to do some benefit to the construction of specialized courses.
\end{abstract}

\section{Introduction}

Specialized courses is an important support in the scheme of talent cultivation. Students can improve their specialty and ability for solving problems by specialized knowledge. Overall and high-quality course construction is the necessary way for improving the teaching quality of specialized courses. And it is the key point to the construction that how to plan the construction of specialized courses and which aspect the construction shouldbe focued on.

In order to highlight how to take the demand of talent cultivation as the traction for overall construction planning of specialized courses, the the following measures are taken: optimizing the system of teaching content, comprehensively reforming teaching mode, vigorously strengthening the construction of teaching resources, and building high-quality teaching team, which combines the typical construction of specialized courses.

\section{Optimizing teaching content system by taking the demand of talent cultivation as the traction}

Teaching content system is the core of specialized courses, which has close relation with the demand of talent cultivation. It is reflected in every aspect such as course standard, teaching materials and teaching plans and so on. For the teaching content system, the two jobs are focued on: one is the cultivation of application ability which combines theory with practice; the other is to make students master the cutting-edge knowledge so that they can take the latest scientific research achievements into teaching materials and the class in a timely manner.

Making systematic plans on teaching content system.

The construction of specialized courses should highlight the cultivation of application ability and make systematic plans on teaching content system. According to the thinking of transformation that paying more attention to the engineering practice than theoretical knowledge, we can build the teaching content system and strengthen the connections between the theory and the practice, which can effectively combine what the students way work on in the future with what the specialized courses teach currently, thus strengthen the practicality and applicability.

\section{Providing continuously updates on teaching content.}

The construction of specialized courses should take the latest scientific research achievements into teaching materials and the class in a timely manner to provide continuous updates on teaching content. In order to maintain the advancement and frontier of teaching content, the team of courses construction should continuously add the latest scientific research achievements and cutting-edge knowledge timely into the teaching materials. It can improve the pertinence of specialized courses content. 


\section{Carrying out reform on teaching modes Oriented teaching content system}

The innovation of teaching modes is the important support to the student's ability realized. The construction of specialized courses should be mainly carried out from following aspects: based on tasks and problems in traction, actively improving teaching methods; focused on the demand of the quality and ability, increasing practice; paying attention to the ability evaluation and roundly implementing the comprehensive assessment.

\section{Reforming teaching methods.}

We should emphasize "teaching as the leading factor", strengthen the research for the case-driven and task-driven teaching methods, and comprehensively use kinds of teaching methods such as task-driven, case-analysis, problem-driven, practice test and interactive discuss methods to carry out teaching. In order to make the innovation of teaching modes really implement into the class, the point-to-area construction of courses should be done and the teaching plan should be made elaborately which build boutique classroom in different subjects for different core units.

The first step is reforming teaching methodologies based on mission requirements for traction, with task as the drive. The second step is reforming teaching methodologies through combining typical case, focusing on the main problems in specialized field, and strengthening case analysis and interactive discussion. The third step is explaining the newest research results both at home which provides theoretical and technical support of solving the actual problems. The last is deepening the understanding of knowledge by practice sessions.

\section{Arranging practice sessions.}

Emphasizing "learning as the main body", in view of the problems in specialized courses content that there is too much abstract theory and it is difficult to organize field practice sessions, the way of comprehensive practice sessions to carry out the practice teaching can be used.

One is to carry out the comprehensive practice sessions in the teaching process. The way of group work in the ordinary time and pick actual problems in specialized field, finally complete the comprehensive practice sessions is taken. The another is using modeling and simulation to carry out experiment-featured teaching for real objects and practical problems in the last teaching link, which is aimed at comprehensive practice ability cultivation.

\section{Making consecutive assessment.}

Change the traditional quality view that knowledge inheritance as the standard. Take consecutive assessment method, highlight the power of process assessment, quantify evaluation of students to the whole process of students learning. Every class and every teaching assessment, the performance of students always link up with their grades to inspire learning enthusiasm of students.

Specifically, it is to pay attention to bring the results of the ordinary work, class performance, comprehensive practice and experiment report into the evaluation system, and gradually strengthen the assessment of students' ability of comprehensive practice, hereby change its life-determining nature. Make the students learning attitude change from the "cram" to "normal effort".

\section{Strengthening resource-relate construction to reform on teaching modes}

The resource-related construction is the important support for the curriculum teaching, which means the construction of specialized courses should focus on the teaching materials system, Internet-based teaching platforms and experiment-featured teaching platforms. It lays a foundation for specialized courses teaching.

\section{Constructing teaching materials system.}

The construction of specialized courses should be closely related with the latest research achievements in the field. Then teaching main materials should be continuously revised intowhich new knowledge, new content should added. At the same time, the auxiliary teaching materials should be enriched and improved, thereby a complete teaching materials system is formed. Teaching 
materials system should include the books of authority and kinds of standards both at home and abroad. It also should include theoretical teaching materials, case bank materials and experiment instructions, etc.

\section{Constructing Internet-based teaching platforms.}

Because most specialized courses are multifarious and abstract theory courses, undergraduates cannot achieve the improvement of quality and ability if they only learn in class. The construction of specialized courses, therefore, should construct Internet-based teaching platforms which provides a wealth of teaching resources and the test library. Students can carry out independent study after class, and really do as the concept of "teaching as the leading factor, learning as the main body".

\section{Constructing experiment-featured teaching platforms.}

In order to cooperate with teaching practice sessions, the construction of specialized courses should also actively construct experiment-featured teaching platforms, establish the corresponding lab and carry out the related hardware and software construction. Through independent research and development or the procurement of mature software, it can provide technical support to solving the actual problems in the specialized field.

\section{Building high-quality teaching teams to support for first-line teaching}

If there is no good teaching team, all the consummate teaching content system, advanced teaching modes and enough teaching resources is a castle in the air. Therefore, teaching team is also important to the construction of specialized courses. The ways can be taken to improve teacher team's level such as sending teachers out to learn how to teach, asking excellent teachers to teach students and teacher's self-improvement. Teaching team construction shouldbe strengthenedto build a high-quality teaching team with reasonable knowledge structure, which fully meets the demand of teaching.

\section{Cultivating awareness.}

It is important to cultivate responsibility, competition and innovation awareness. The teaching team's positive awareness should be built through the implementation of kinds of ways like "the regular to check class", "the whole-process in class" and "learning one to one".

\section{Strengthening internal and external communication.}

Well-known experts and professors are invited activelly to transmitting scriptures and delivering treasures. It not only brings specialized guidance by experts and professors engaged in related fields, but also provides salutary lessons about teaching content and teaching methodologies.

Through regular collective lesson preparation, simulating teaching, education theory study and experience communication, the teaching team gradually cultivate great awareness such as "quality education", "innovation practice education" and "learning as the main body, teaching as the leading factor".

\section{Laying emphasis upon teaching outcomes.}

By reporting project achievements in teaching research, writing teaching theses, teachers constantly summ up experience and achievements. It is benefit to the transformation and application of teaching achievements as well as provides strong support for frontline teaching.

\section{Summary}

In conclusion, the construction of specialized courses should revolve around the demand of talent cultivation. Cultivating students' ability is impotrtant and the quality of specialized courses construction should be improved from the aspect of teaching content system, reforming teaching methodologies shoring up teaching resource-related and building high-quality teaching teams. 